\title{
Best proximity point theorems for weakly contractive mapping and weakly Kannan mapping in partial metric spaces
}

Jingling Zhang and Yongfu Su*

\section{"Correspondence:}

suyongfu@gmail.com

Department of Mathematics, Tianjin

Polytechnic University, Tianjin,

300387, China

\begin{abstract}
The purpose of this paper is to obtain best proximity point theorems for a weakly contractive mapping and a weakly Kannan mapping in partial metric spaces. In this paper, the P-operator technique, which changes a non-self mapping to a self mapping, provides a key method. Many recent results in this area have been improved.

MSC: $47 \mathrm{H} 05 ; 47 \mathrm{H} 09 ; 47 \mathrm{H} 10$

Keywords: fixed point; best proximity point; weakly contractive mapping; P-property; partial metric
\end{abstract}

\section{Introduction and preliminaries}

Let us recall some basic definitions of a partial metric space and its properties which can be found in [1].

Definition 1.1 A partial metric on a nonempty set $X$ is a function $p: X \times X \rightarrow R^{+}$such that for all $x, y, z \in X$ :

$\left(\mathrm{p}_{1}\right) \quad x=y \Leftrightarrow p(x, x)=p(x, y)=p(y, y)$,

$\left(\mathrm{p}_{2}\right) p(x, x) \leq p(x, y)$,

( $\left.\mathrm{p}_{3}\right) p(x, y)=p(y, x)$,

$\left(\mathrm{p}_{4}\right) \quad p(x, y) \leq p(x, z)+p(z, y)-p(z, z)$.

A partial metric space is a pair $(X, p)$ such that $X$ is a nonempty set and $p$ is a partial metric on $X$.

We can see from $\left(\mathrm{p}_{1}\right)$ and $\left(\mathrm{p}_{2}\right)$ that $p(x, y)=0$ implies $x=y$. However, the converse is not necessarily true. A typical example of this situation is provided by the partial metric space $\left(R^{+}, p_{\max }\right)$, where the function $p_{\max }: R^{+} \times R^{+} \rightarrow R^{+}$is defined by $p_{\max }(x, y)=\max \{x, y\}$ for all $x, y \in R^{+}$. Other examples of partial metric spaces which are interesting from a computational point of view may be found in [1] and [2].

Following [1], each partial metric $p$ on $X$ generates a $T_{0}$ topology $\tau(p)$ on $X$, whose base is a family of open $p$-balls:

$$
\left\{B_{p}(x, \varepsilon): x \in X, \varepsilon>0\right\},
$$

@2014 Zhang and Su; licensee Springer. This is an Open Access article distributed under the terms of the Creative Commons Attribution License (http://creativecommons.org/licenses/by/2.0), which permits unrestricted use, distribution, and reproduction in any medium, provided the original work is properly cited. 
where $B_{p}(x, \varepsilon)=\{y \in X: p(x, y) \leq p(x, x)+\varepsilon\}$ for all $x \in X$ and $\varepsilon>0$. Definitions of convergence, Cauchy sequence, completeness and continuity on partial metric spaces are as follows:

$\left(\mathrm{d}_{1}\right)$ A sequence $\left\{x_{n}\right\}$ in a partial metric space $(X, p)$ converges to $x$ if and only if $p(x, x)=$ $\lim _{n \rightarrow \infty} p\left(x, x_{n}\right)$.

$\left(\mathrm{d}_{2}\right)$ A sequence $\left\{x_{n}\right\}$ in a partial metric space $(X, p)$ is called a Cauchy sequence if $\lim _{n, m \rightarrow \infty} p\left(x_{n}, x_{m}\right)$ exists and is finite.

$\left(\mathrm{d}_{3}\right)$ A partial metric space $(X, p)$ is called complete if every Cauchy sequence $\left\{x_{n}\right\}$ in $X$ converges, with respect to $\tau(p)$, to a point $x \in X$ such that $p(x, x)=\lim _{n, m \rightarrow \infty} p\left(x_{n}, x_{m}\right)$.

( $\left.\mathrm{d}_{4}\right)$ A mapping $f: X \rightarrow X$ is said to be continuous at $x_{0} \in X$ if for every $\varepsilon>0$, there exists $\delta>0$ such that $f\left(B_{p}\left(x_{0}, \delta\right)\right) \subseteq B_{p}\left(f\left(x_{0}\right), \varepsilon\right)$.

It can be easily verified that the function $d_{p}: X \times X \rightarrow R^{+}$defined by

$$
d_{p}(x, y)=2 p(x, y)-p(x, x)-p(y, y)
$$

is a metric on $X$. The following useful remarks were introduced in [1]:

$\left(\mathrm{r}_{1}\right)$ If a sequence converges in a partial metric space $(X, p)$ with respect to $\tau\left(d_{p}\right)$, then it converges with respect to $\tau(p)$. Of course, the converse is not true.

$\left(\mathrm{r}_{2}\right)$ A sequence $\left\{x_{n}\right\}_{n \in N}$ in a partial metric space $(X, p)$ is a Cauchy sequence if and only if it is a Cauchy sequence in the metric space $\left(X, d_{p}\right)$.

$\left(\mathrm{r}_{3}\right)$ A partial metric space $(X, p)$ is complete if and only if the metric space $\left(X, d_{p}\right)$ is complete.

$\left(r_{4}\right)$ Given a sequence $\left\{x_{n}\right\}_{n \in N}$ in a partial metric space $(X, p)$ and $x \in X$, we have that

$$
\lim _{n \rightarrow \infty} d_{p}\left(x, x_{n}\right)=0 \quad \Leftrightarrow \quad p(x, x)=\lim _{n \rightarrow \infty} p\left(x, x_{n}\right)=\lim _{n, m \rightarrow \infty} p\left(x_{n}, x_{m}\right) .
$$

Let $A$ and $B$ be nonempty subsets of a metric space $(X, d)$. An operator $T: A \rightarrow B$ is said to be contractive if there exists $k \in[0,1)$ such that $d(T x, T y) \leq k d(x, y)$ for any $x, y \in A$. The well-known Banach contraction principle says: Let $(X, d)$ be a complete metric space, and let $T: X \rightarrow X$ be a contraction of $X$ into itself; then $T$ has a unique fixed point in $X$.

In the last fifty years, the Banach contraction principle has been extensively studied and generalized on many settings. One of the generalizations is a weakly contractive mapping.

Definition 1.2 ([3]) Let $(X, d)$ be a metric space. A mapping $f: X \rightarrow X$ is said to be weakly contractive provided that

$$
d(f(x), f(y)) \leq \bar{\alpha}(x, y) d(x, y)
$$

for all $x, y \in X$, where the function $\bar{\alpha}: X \times X \rightarrow[0,1)$, holds for every $0<a<b$ that

$$
\theta(a, b)=\sup \{\bar{\alpha}(x, y): a \leq d(x, y) \leq b\}<1 .
$$

The fixed point theorem for a weakly contractive mapping was presented in [3].

Theorem 1.3 Let $(X, d)$ be a complete metric space. If $: X \rightarrow X$ is a weakly contractive mapping, then $f$ has a unique fixed point $x^{*}$ and the Picard sequence of iterates $\left\{f^{n}(x)\right\}_{n \in N}$ converges, for every $x \in X$, to $x^{*}$. 
One type of contraction which is different from the Banach contraction is Kannan mappings. In [4], Kannan obtained the following fixed point theorem.

Theorem $1.4([4])$ Let $(X, d)$ be a complete metric space, and let $f: X \rightarrow X$ be a mapping such that

$$
d(f(x), f(y)) \leq \frac{\alpha}{2}[d(x, f(x))+d(y, f(y))]
$$

for all $x, y \in X$ and some $\alpha \in[0,1]$, then $f$ has a unique fixed point $x^{*} \in X$. Moreover, the Picard sequence of iterates $\left\{f^{n}(x)\right\}_{n \in N}$ converges, for every $x \in X$, to $x^{*}$.

In [5], the authors introduced a more general weakly Kannan mapping and obtained its fixed point theorem.

Definition 1.5 ([5]) Let $(X, d)$ be a metric space. A mapping $f: X \rightarrow X$ is said to be weakly Kannan if there exists $\bar{\alpha}: X \times X \rightarrow[0,1)$ which satisfies, for every $0<a \leq b$ and for all $x, y \in X$, that

$$
\theta(a, b)=\sup \{\bar{\alpha}(x, y): a \leq d(x, y) \leq b\}<1
$$

and

$$
d(f(x), f(y)) \leq \frac{\bar{\alpha}(x, y)}{2}[d(x, f(x))+d(y, f(y))] .
$$

Theorem 1.6 ([5]) Let $(X, d)$ be a complete metric space. If $: X \rightarrow X$ is a weakly Kannan mapping, then $f$ has a unique fixed point $x^{*}$ and the Picard sequence of iterates $\left\{f^{n}(x)\right\}_{n \in N}$ converges, for every $x \in X$, to $x^{*}$.

Recently, Alghamdi et al. [6] generalized the weakly contractive and weakly Kannan mappings to partial metric spaces and obtained the following fixed point theorems.

Definition 1.7 ([6]) Let $(X, p)$ be a partial metric space. A mapping $f: X \rightarrow X$ is said to be weakly contractive provided that there exists $\bar{\alpha}: X \times X \rightarrow[0,1)$ such that for every $0 \leq a \leq b$,

$$
\theta(a, b)=\sup \{\bar{\alpha}(x, y): a \leq p(x, y) \leq b\}<1,
$$

and for every $x, y \in X$,

$$
p(f(x), f(y)) \leq \bar{\alpha}(x, y) p(x, y) .
$$

Definition 1.8 ([6]) Let $(X, p)$ be a partial metric space. A mapping $f: X \rightarrow X$ is said to be weakly Kannan if there exists $\bar{\alpha}: X \times X \rightarrow[0,1)$ which satisfies for every $0<a \leq b$ and for all $x, y \in X$ that

$$
\theta(a, b)=\sup \{\bar{\alpha}(x, y): a \leq p(x, y) \leq b\}<1
$$


and

$$
p(f(x), f(y)) \leq \frac{\bar{\alpha}(x, y)}{2}[p(x, f(x))+p(y, f(y))] .
$$

Theorem 1.9 ([6]) Let $(X, p)$ be a complete partial metric space, and let $f: X \rightarrow X$ be a weakly contractive mapping. Then $f$ has a unique fixed point $x^{*} \in X$ and the Picard sequence of iterates $\left\{f^{n}(x)\right\}_{n \in N}$ converges, with respect to $\tau\left(d_{p}\right)$, for every $x \in X$, to $x^{*}$. Moreover, $p\left(x^{*}, x^{*}\right)=0$.

Theorem 1.10 ([6]) Let $(X, p)$ be a complete partial metric space, and let $f: X \rightarrow X$ be a weakly Kannan mapping. Then $f$ has a unique fixed point $x^{*} \in X$ and the Picard sequence of iterates $\left\{f^{n}(x)\right\}_{n \in N}$ converges, with respect to $\tau\left(d_{p}\right)$, for every $x \in X$, to $x^{*}$. Moreover, $p\left(x^{*}, x^{*}\right)=0$.

In this paper, we first obtain best proximity point theorems for a weakly contractive mapping and a weakly Kannan mapping in partial metric spaces. The $P$-operator technique, which changes a non-self mapping to a self mapping, provides a key method. Many recent results in this area have been improved.

Before giving the main results, we need the following notations and basic facts.

Let $A, B$ be two nonempty subsets of a complete partial metric space $(X, p)$ and consider a mapping $T: A \rightarrow B$. The best proximity point problem is whether we can find an element $x_{0} \in A$ such that $p\left(x_{0}, T x_{0}\right)=p(A, B)$, where $p(A, B)=\inf \{p(x, y): x \in A$ and $y \in B\}$. Since $p(x, T x) \geq p(A, B)$ for any $x \in A$, in fact, the optimal solution to this problem is the one for which the value $p(A, B)$ is attained. Some works on the best proximity point problem can be found in [7-11].

Let $A$ and $B$ be two nonempty subsets of a partial metric space $(X, p)$. We denote by $A_{0}$ and $B_{0}$ the following sets:

$$
\begin{aligned}
& A_{0}=\{x \in A: p(x, y)=p(A, B) \text { for some } y \in B\}, \\
& B_{0}=\{y \in B: p(x, y)=p(A, B) \text { for some } x \in A\} .
\end{aligned}
$$

\section{Best proximity point theorems in partial metric spaces}

Definition 2.1 Let $(A, B)$ be a pair of nonempty subsets of a partial metric space $(X, p)$. A mapping $f: A \rightarrow B$ is said to be weakly contractive provided that

$$
p(f(x), f(y)) \leq \bar{\alpha}(x, y) p(x, y)
$$

for all $x, y \in A$, where the function $\bar{\alpha}: A \times A \rightarrow[0,1)$, holds for every $0<a<b$ that

$$
\theta(a, b)=\sup \{\bar{\alpha}(x, y): a \leq p(x, y) \leq b\}<1 .
$$

Definition 2.2 Let $(A, B)$ be a pair of nonempty subsets of a partial metric space $(X, p)$. A mapping $f: A \rightarrow B$ is said to be weakly Kannan provided that

$$
p(f(x), f(y)) \leq \frac{\bar{\alpha}(x, y)}{2}[p(x, f(x))+p(y, f(y))-2 p(A, B)]
$$


for all $x, y \in A$, where the function $\bar{\alpha}: A \times A \rightarrow[0,1)$, holds for every $0<a<b$ that

$$
\theta(a, b)=\sup \{\bar{\alpha}(x, y): a \leq p(x, y) \leq b\}<1 .
$$

We rewrite the $P$-property in the setting of partial metric spaces as follows.

Definition 2.3 Let $(A, B)$ be a pair of nonempty subsets of a partial metric space $(X, p)$ with $A_{0} \neq \emptyset$. Then the pair $(A, B)$ is said to have the $P$-property if and only if, for any $x_{1}, x_{2} \in$ $A_{0}$ and $y_{1}, y_{2} \in B_{0}$,

$$
\left\{\begin{array}{l}
p\left(x_{1}, y_{1}\right)=p(A, B), \\
p\left(x_{2}, y_{2}\right)=p(A, B)
\end{array} \quad \Rightarrow \quad p\left(x_{1}, x_{2}\right)=p\left(y_{1}, y_{2}\right) .\right.
$$

Lemma 2.4 Let $(X, p)$ be a partial metric space, then $p$ is a continuous function, that is, for any $x_{n}, y_{n}, x, y \subseteq X$, if $x_{n} \rightarrow x, y_{n} \rightarrow y$, then $p\left(x_{n}, y_{n}\right) \rightarrow p(x, y)$ as $n \rightarrow \infty$.

Proof Since

$$
\begin{aligned}
p\left(x_{n}, y_{n}\right) & \leq p\left(x_{n}, x\right)+p\left(x, y_{n}\right)-p(x, x) \\
& \leq p\left(x_{n}, x\right)+p(x, y)+p\left(y, y_{n}\right)-p(x, x)-p(y, y) .
\end{aligned}
$$

From the above inequality, we can get that

$$
\begin{aligned}
& p\left(x_{n}, y_{n}\right)-p(x, y) \\
& \quad \leq\left[p\left(x_{n}, x\right)-p(x, x)\right]+\left[p\left(y, y_{n}\right)-p(y, y)\right] \rightarrow 0 \quad \text { as } n \rightarrow \infty .
\end{aligned}
$$

On the other hand, we have

$$
\begin{aligned}
p(x, y) & \leq p\left(x, x_{n}\right)+p\left(x_{n}, y\right)-p\left(x_{n}, x_{n}\right) \\
& \leq p\left(x, x_{n}\right)+p\left(x_{n}, y_{n}\right)+p\left(y_{n}, y\right)-p\left(x_{n}, x_{n}\right)-p\left(y_{n}, y_{n}\right) .
\end{aligned}
$$

Then we can obtain

$$
\begin{aligned}
& p(x, y)-p\left(x_{n}, y_{n}\right) \\
& \quad \leq\left[p\left(x, x_{n}\right)-p\left(x_{n}, x_{n}\right)\right]+\left[p\left(y_{n}, y\right)-p\left(y_{n}, y_{n}\right)\right] \rightarrow 0 \quad \text { as } n \rightarrow \infty .
\end{aligned}
$$

Above all, we can get that

$$
\left|p\left(x_{n}, y_{n}\right)-p(x, y)\right| \rightarrow 0 \quad \text { as } n \rightarrow \infty
$$

This completes the proof.

Remark For $\left(\mathrm{r}_{4}\right)$ we know that, for any $x_{n}, y_{n}, x, y \subseteq X$, if $d_{p}\left(x_{n}, x\right) \rightarrow 0, d_{p}\left(y_{n}, y\right) \rightarrow 0$, then $p\left(x_{n}, y_{n}\right) \rightarrow p(x, y)$ as $n \rightarrow \infty$. 
Theorem 2.5 Let $(A, B)$ be a pair of nonempty closed subsets of a complete partial metric space $(X, p)$ such that $A_{0} \neq \emptyset$. Let $T: A \rightarrow B$ be a continuous weakly contractive mapping. Suppose that $T\left(A_{0}\right) \subseteq B_{0}$ and the pair $(A, B)$ has the P-property. Then $T$ has a unique best proximity point $x^{*} \in A_{0}$ and the iteration sequence $\left\{x_{2 k}\right\}_{n=0}^{\infty}$ defined by

$$
x_{2 k+1}=T x_{2 k}, \quad p\left(x_{2 k+2}, x_{2 k+1}\right)=p(A, B), \quad k=0,1,2, \ldots
$$

converges, with respect to $\tau\left(d_{p}\right)$, for every $x_{0} \in A_{0}$, to $x^{*}$.

Proof We first prove that $B_{0}$ is closed with respect to $\left(X, d_{p}\right)$. Let $\left\{y_{n}\right\} \subseteq B_{0}$ be a sequence such that $y_{n} \rightarrow q \in B$. It follows from the $P$-property that

$$
\begin{aligned}
d_{p}\left(y_{n}, y_{m}\right) & =2 p\left(y_{n}, y_{m}\right)-p\left(y_{n}, y_{n}\right)-p\left(y_{m}, y_{m}\right) \\
& =2 p\left(x_{n}, x_{m}\right)-p\left(x_{n}, x_{n}\right)-p\left(x_{m}, x_{m}\right) \\
& =d_{p}\left(x_{n}, x_{m}\right) .
\end{aligned}
$$

Hence

$$
d_{p}\left(y_{n}, y_{m}\right) \rightarrow 0 \quad \Rightarrow \quad d_{p}\left(x_{n}, x_{m}\right) \rightarrow 0
$$

as $n, m \rightarrow \infty$, where $x_{n}, x_{m} \in A_{0}$ and $p\left(x_{n}, y_{n}\right)=p(A, B), p\left(x_{m}, y_{m}\right)=p(A, B)$. Then $\left\{x_{n}\right\}$ is a Cauchy sequence in $\left(X, d_{p}\right)$, so that $\left\{x_{n}\right\}$ converges to a point $p \in A$. By the continuity of a partial metric $p$, we have $p(p, q)=p(A, B)$, that is, $q \in B_{0}$, and hence $B_{0}$ is closed with respect to $\left(X, d_{p}\right)$.

Let $\bar{A}_{0}$ be the closure of $A_{0}$ in a metric space $\left(X, d_{p}\right)$, we claim that $T\left(\bar{A}_{0}\right) \subseteq B_{0}$. In fact, if $x \in \bar{A}_{0} \backslash A_{0}$, then there exists a sequence $\left\{x_{n}\right\} \subseteq A_{0}$ such that $x_{n} \rightarrow x$. By the continuity of $T$ and the closedness of $B_{0}$, we have $T x=\lim _{n \rightarrow \infty} T x_{n} \in B_{0}$; that is, $T\left(\bar{A}_{0}\right) \subseteq B_{0}$.

Define an operator $P_{A_{0}}: T\left(\bar{A}_{0}\right) \rightarrow A_{0}$ by $P_{A_{0}} y=\left\{x \in A_{0}: p(x, y)=p(A, B)\right\}$. Since the pair $(A, B)$ has the $P$-property, we have

$$
p\left(P_{A_{0}} T x_{1}, P_{A_{0}} T x_{2}\right)=p\left(T x_{1}, T x_{2}\right) \leq \bar{\alpha}\left(x_{1}, x_{2}\right) p\left(x_{1}, x_{2}\right)
$$

for any $x_{1}, x_{2} \in \bar{A}_{0}$. This shows that $P_{A_{0}} T: \bar{A}_{0} \rightarrow \bar{A}_{0}$ is a weak contraction from a complete partial metric subspace $\bar{A}_{0}$ into itself. Using Theorem 1.9, we can get that $P_{A_{0}} T$ has a unique fixed point $x^{*}$; that is, $P_{A_{0}} T x^{*}=x^{*} \in A_{0}$, which implies that

$$
p\left(x^{*}, T x^{*}\right)=p(A, B) .
$$

Therefore, $x^{*}$ is the unique one in $A_{0}$ such that $p\left(x^{*}, T x^{*}\right)=p(A, B)$. And the Picard iteration sequence $\left\{\left(P_{A_{0}} T\right)^{n} x_{0}\right\}_{n \in N}$ converges, with respect to $\tau\left(d_{p}\right)$, for every $x_{0} \in A_{0}$, to $x^{*}$. Since the iteration sequence $\left\{x_{2 k}\right\}_{n=0}^{\infty}$ defined by

$$
x_{2 k+1}=T x_{2 k}, \quad p\left(x_{2 k+2}, x_{2 k+1}\right)=p(A, B), \quad k=0,1,2, \ldots
$$

is exactly the subsequence of $\left\{x_{n}\right\}$, so that it converges, for every $x_{0} \in A_{0}$, to $x^{*}$. This completes the proof. 
Theorem 2.6 Let $(A, B)$ be a pair of nonempty closed subsets of a complete partial metric space $(X, p)$ such that $A_{0} \neq \emptyset$. Let $T: A \rightarrow B$ be a continuous weakly Kannan mapping. Suppose that $T\left(A_{0}\right) \subseteq B_{0}$ and the pair $(A, B)$ has the P-property. Then $T$ has a unique best proximity point $x^{*} \in A_{0}$ and the iteration sequence $\left\{x_{2 k}\right\}_{n=0}^{\infty}$ defined by

$$
x_{2 k+1}=T x_{2 k}, \quad p\left(x_{2 k+2}, x_{2 k+1}\right)=p(A, B), \quad k=0,1,2, \ldots
$$

converges, with respect to $\tau\left(d_{p}\right)$, for every $x_{0} \in A_{0}$, to $x^{*}$.

Proof We can prove that $B_{0}$ is closed and $T\left(\bar{A}_{0}\right) \subseteq B_{0}$ in the same way as in Theorem 2.5. Now define an operator $P_{A_{0}}: T\left(\bar{A}_{0}\right) \rightarrow A_{0}$ by $P_{A_{0}} y=\left\{x \in A_{0}: p(x, y)=p(A, B)\right\}$. Since the pair $(A, B)$ has the $P$-property, we have

$$
\begin{aligned}
p\left(P_{A_{0}} T x_{1}, P_{A_{0}} T x_{2}\right)= & p\left(T x_{1}, T x_{2}\right) \\
\leq & \frac{\bar{\alpha}(x, y)}{2}\left[p\left(x_{1}, T x_{1}\right)+p\left(x_{2}, T x_{2}\right)-2 p(A, B)\right] \\
\leq & \frac{\bar{\alpha}(x, y)}{2}\left[p\left(x_{1}, P_{A_{0}} T x_{1}\right)+p\left(P_{A_{0}} T x_{1}, T x_{1}\right)\right. \\
& \left.+p\left(x_{2}, P_{A_{0}} T x_{2}\right)+p\left(P_{A_{0}} T x_{2}, T x_{2}\right)-2 p(A, B)\right] \\
= & \frac{\bar{\alpha}(x, y)}{2}\left[p\left(x_{1}, P_{A_{0}} T x_{1}\right)+p\left(x_{2}, P_{A_{0}} T x_{2}\right)\right]
\end{aligned}
$$

for any $x_{1}, x_{2} \in \bar{A}_{0}$. This shows that $P_{A_{0}} T: \bar{A}_{0} \rightarrow \bar{A}_{0}$ is a weakly Kannan mapping from a complete partial metric subspace $\bar{A}_{0}$ into itself. Using Theorem 1.10, we can get that $P_{A_{0}} T$ has a unique fixed point $x^{*}$; that is, $P_{A_{0}} T x^{*}=x^{*} \in A_{0}$, which implies that

$$
p\left(x^{*}, T x^{*}\right)=p(A, B) .
$$

Therefore, $x^{*}$ is the unique one in $A_{0}$ such that $p\left(x^{*}, T x^{*}\right)=p(A, B)$. And the Picard iteration sequence $\left\{\left(P_{A_{0}} T\right)^{n} x_{0}\right\}_{n \in N}$ converges, with respect to $\tau\left(d_{p}\right)$, for every $x_{0} \in A_{0}$, to $x^{*}$. Since the iteration sequence $\left\{x_{2 k}\right\}_{n=0}^{\infty}$ defined by

$$
x_{2 k+1}=T x_{2 k}, \quad p\left(x_{2 k+2}, x_{2 k+1}\right)=p(A, B), \quad k=0,1,2, \ldots
$$

is exactly the subsequence of $\left\{x_{n}\right\}$, so that it converges, for every $x_{0} \in A_{0}$, to $x^{*}$. This completes the proof.

Competing interests

The authors declare that they have no competing interests.

Authors' contributions

All authors contributed equally and significantly in writing this article. All authors read and approved the final manuscript.

Acknowledgements

This project is supported by the National Natural Science Foundation of China under grant (11071279).

Received: 24 October 2013 Accepted: 10 February 2014 Published: 25 Feb 2014 


\section{References}

1. Matthews, SG: Partial metric topology. Ann. N.Y. Acad. Sci. 728, 183-197 (1994)

2. Escardo, MH: PCF extended with real numbers. Theor. Comput. Sci. 162, 79-115 (1996)

3. Dugundji, J, Granas, A: Weakly contractive mappings and elementary domain invariance theorem. Bull. Greek Math Soc. 19, 141-151 (1978)

4. Kannan, R: Some results on fixed points. Bull. Calcutta Math. Soc. 60, 71-76 (1968)

5. Ariza-Ruiz, D, Jimenez-Melando, A: A continuation method for weakly Kannan mappings. Fixed Point Theory Appl. 2010, Article ID 321594 (2010)

6. Alghamdi, MA, Shahzad, N, Valero, O: On fixed point theory in partial metric spaces. Fixed Point Theory Appl. 2012, 175 (2012)

7. Gabeleh, M: Global optimal solutions of non-self mappings. U.P.B. Sci. Bull., Ser. A 75, 67-74 (2013)

8. Zhang, J, Su, Y, Cheng, Q: A note on 'A best proximity point theorem for Geraghty-contractions'. Fixed Point Theory Appl. 2013, 99 (2013)

9. Al-Thagafi, MA, Shahzad, N: Convergence and existence results for best proximity points. Nonlinear Anal. 70, 3665-3671 (2009)

10. Eldred, AA, Veeramani, P: Existence and convergence of best proximity points. J. Math. Anal. Appl. 323, 1001-1006 (2006)

11. Alghamdi, MA, Shahzad, N, Vetro, F: Best proximity points for some classes of proximal contractions. Abstr. Appl. Anal. 2013, Article ID 713252 (2013)

10.1186/1687-1812-2014-50

Cite this article as: Zhang and Su: Best proximity point theorems for weakly contractive mapping and weakly Kannan mapping in partial metric spaces. Fixed Point Theory and Applications 2014, 2014:50

\section{Submit your manuscript to a SpringerOpen ${ }^{\circ}$ journal and benefit from:}

- Convenient online submission

- Rigorous peer review

- Immediate publication on acceptance

- Open access: articles freely available online

- High visibility within the field

- Retaining the copyright to your article 